\title{
Primary Care Physicians' Collection, Comfort, and Use of Race and Ethnicity in Clinical Practice in the United States
}

\author{
Vence L. Bonham, ${ }^{1, * \dagger}$ Nkeiruka I. Umeh, ${ }^{1,2 \dagger}$ Brooke A. Cunningham, Khadijah E. Abdallah, \\ Sherrill L. Sellers, and Lisa A. Cooper ${ }^{5}$
}

\begin{abstract}
Purpose: The clinical utility of race and ethnicity has been debated. It is important to understand if and how race and ethnicity are communicated and collected in clinical settings. We investigated physicians' self-reported methods of collecting a patient's race and ethnicity in the clinical encounter, their comfort with collecting race and ethnicity, and associations with use of race in clinical decision-making.

Methods: A national cross-sectional study of 787 clinically active general internists in the United States. Physicians' self-reported comfort with collecting patient race and ethnicity, their collection practices, and use of race in clinical care were assessed. Bivariate and multivariable regression analyses were conducted to examine associations between comfort, collection practices, and use of race.

Results: Most physicians asked patients to self-report their race or ethnicity (26.5\%) on an intake form or collected this information directly from patients (26.2\%). Most physicians were comfortable collecting patient race and ethnicity (84.3\%). Physicians who were more comfortable collecting patient race and ethnicity ( $\beta=1.65$; [95\% confidence interval; $\mathrm{Cl} 0.03-3.28])$ or who directly collected patients' race and ethnicity $(\beta=1.24[95 \% \mathrm{Cl} 0.07-2.41])$ were more likely to use race in clinical decision-making than physicians who were uncomfortable.

Conclusions: This study documents variation in physician comfort level and practice patterns regarding patient race and ethnicity data collection. As the U.S. population becomes more diverse, future work should examine how physicians speak about race and ethnicity with patients and their use of race and ethnicity data impact patient-physician relationships, clinical decision-making, and patient outcomes.
\end{abstract}

Keywords: clinical decision-making; collection of race and ethnicity; physician behavior; physicians' use of race; RACE scale

\section{Introduction}

Race and ethnicity, along with a battery of other demographic data, are used by insurers, healthcare organizations, and clinicians as a means of monitoring quality of care and identifying and addressing healthcare inequi- ties. ${ }^{1,2}$ Patient race and ethnicity are also used by clinicians in decision-making for prescribing medications (e.g., Isosorbide dinitrate/hydralazine, Carbamazepine, and ACE inhibitors), ${ }^{3-5}$ ordering diagnostic tests (e.g., lung function and coronary heart disease), ${ }^{6,7}$ and determining when to

\footnotetext{
'Social and Behavioral Research Branch, National Human Genome Research Institute, National Institutes of Health, Bethesda, Maryland.

${ }^{2}$ Albany Medical College, Albany, New York.

${ }^{3}$ Department of Family Medicine and Community Health, University of Minnesota Medical School, Minneapolis, Minnesota.

${ }^{4}$ College of Education, Health and Society, Miami University, Oxford, Ohio.

${ }^{5}$ Department of Medicine, Johns Hopkins University School of Medicine, Baltimore, Maryland.

${ }^{\dagger}$ Co-first authors.
}

*Address correspondence to: Vence L. Bonham, JD, Social and Behavioral Research Branch, National Human Genome Research Institute, National Institutes of Health, 31 Center Drive, Building 31, Room B1B37-G, Bethesda, MD 20892-2152, E-mail: bonhamv@mail.nih.gov 
initiate screening (e.g., colorectal cancer and diabetes). ${ }^{8,9}$ Self-identified race and ethnicity (SIRE) are also used as a surrogate for other information, such as culture and social experiences. ${ }^{10-15}$

The concepts of race and ethnicity have varying definitions and both terms are often conflated and used interchangeably. ${ }^{16,17}$ Race is a social construct; the Institute of Medicine (IOM) report Unequal Treatment: Confronting Racial and Ethnic Disparities in Healthcare defined race as "a socioeconomic concept wherein groups of people sharing physical characteristics are treated differently based on stereotypical thinking, discriminatory institutions and social structures, a shared worldview, and social myths."2,17, In addition, race is often used as a biological metric to infer genetic ancestry between different population groups. ${ }^{18,19}$ In the United States, it has been used since the 17th century to subdivide humans from one another phenotypically. ${ }^{20,21}$ However, race is a fluid construct; a person's racial identity can change over time and self-ascribed race can differ from assigned race. ${ }^{22}$ Contrastingly, ethnicity, used as a sociocultural construct, ${ }^{9,16}$ often refers to shared cultural identification, religion, and language. ${ }^{18}$

Some researchers have investigated whether genetic ancestral informative markers (AIMS) may provide a more "objective and accurate method" of study of racial and ethnic groups in population disease studies. ${ }^{23}$ Burchard and colleagues conducted a study of lungfunction predictions and concluded that current predictive equations, which rely on self-identified race alone, may misestimate lung function among subjects who identify themselves as African American and that, including AIMS in the equation may improve lung-function estimates. ${ }^{6}$ AIMS, however, will not replace the collection of SIRE in the clinical encounter. Genetically quantifying ancestry does not always appropriately capture racial and ethnic social identity and their influence on health.

Within the last 10 years, health plans and medical practices have increased their collection of patients' race and ethnicity data to analyze differences in healthcare utilization and assess the quality of care across different populations. $^{24-29}$ The electronic health record meaningful use program ${ }^{30,31}$ created financial incentives for providers to collect patient demographics, including race and ethnicity. Thus, collection of patient race and ethnicity within health practices has also increased, ${ }^{24,25}$ and various methods have been used to collect these data. ${ }^{32,33}$

Examining how healthcare providers collect patient race and ethnicity and their comfort with data collec- tion provides valuable insights into the different ways that physicians understand race and ethnicity. We hypothesize that physicians' behaviors related to the collection of patient's race and ethnicity will affect how the physicians judge the relevance of the information in the clinical encounter and their comfort with the collection of race and ethnicity. We contend that physicians who directly collect or have patients self-report their race and ethnicity believe it has more clinical utility and are more comfortable with the collection than physicians who report race and ethnicity based upon the physician's or staff's perception of the patient's race and ethnicity or, alternatively, than those who do not collect the information at all.

\section{Methods}

Study design and sample

We conducted a cross-sectional study using data from the Health Professionals' Genetics Education Needs Exploration survey, which was administered from April to December 2010 through the Internet and mail to a United States' sample of 1738 eligible and clinically active general internists. ${ }^{34}$ The sample was drawn from the SK\&A company's physician database, which has more than 87,000 office-based internists. ${ }^{35}$ The sample members were selected in two batches. First, a general random sample $(n=1929)$ of general internists from all racial and ethnic backgrounds was selected from the overall database. This was supplemented by a sample of physicians who graduated from historically black medical schools $(n=193)$ to increase the representation of black physicians in the overall sample and improve the study's ability to detect differences between black physicians and other physicians. Physicians were excluded if they did not have a current (USA) mailing address and/or were not currently clinically active internists per their own selfreport or by report of their office staff. Of the overall sample, 787 responded (a 45\% response rate). The survey included validated measures, which examined physicians' knowledge of genetic variation, use of race in the clinical setting, and beliefs about race and ethnicity. The measures included the Racial Attributes in Clinical Evaluation (RACE) Scale. Further information regarding sampling methodology, scale development, and survey implementation is reported in Bonham et al. ${ }^{34}$ This study was reviewed and approved by the Institutional Review Boards at the National Human Genome Research Institute (\#05-HGN196), Johns Hopkins University, and Miami University of Ohio. 
Study variables

Method of collecting data on patient race and ethnicity. The first predictor variable was collection practices related to patient race and ethnicity. Respondents reported how race or ethnicity was collected in their clinical setting: (1) by a patient's selfreport on an intake form; (2) directly from the patient by a clerk; (3) directly from the patient by a nurse or physician's assistant; (4) directly from the patient by the physician respondent; (5) by the physician respondent's judgment; or (6) by a clerk's judgment. Respondents could also report that data related to patient race or ethnicity were not collected. For analysis, these responses were grouped into three categories: self-report (response 1), direct collection (asking the patient) (responses 2, 3, and 4), and perception-based collection (provider or staff inference) (responses 5 and 6).

Comfort with collecting data on patient race and ethnicity. The second predictor variable was physicians' comfort with the collection of patient racial and ethnic information. This information was assessed through the survey question, "How comfortable are you collecting racial and ethnic data from your patients?" There were five responses: (1) very comfortable; (2) somewhat comfortable; (3) somewhat uncomfortable; (4) very uncomfortable; and (5) never collect racial and ethnic data. For analytical purposes, categories were collapsed and coded as follows: comfortable (responses 1 and 2), uncomfortable (responses 3 and 4), and never collect racial data (response 5).

Physician use of race in clinical decision-making (RACE score). The RACE scale, used as the outcome variable in our multivariable linear regression, measured domains of physicians' explicit use of race in the clinical setting. ${ }^{34}$ The RACE scale consists of seven items and examines the extent to which the respondents consciously employ patient race in clinical decisionmaking. Each item was rated on a five-point Likert scale from 0 (none of the time) to 4 (all of the time). Examples of items include, "I consider my patient's race when determining age of initiation of screening for certain diseases," and "I consider my patient's race when making decisions about which medications to prescribe." Responses to each item were summed, with higher RACE scores indicating greater explicit use of race in clinical decision-making. The lowest score obtainable is 0 , with the highest score possible being 28 (Supplementary Table S1).

\section{Covariates of interest}

The survey collected demographic characteristics of the physicians (e.g., sex, age, years in practice, ethnicity, and race) as well as the estimated racial and ethnic composition of each physician's patient population and the respondent's percentage of time spent seeing patients. For analytical purposes, we grouped the physicians into majority and minority; white physicians were identified as majority physicians, with all other physicians being classified as minority. In addition to this information, respondents were asked the meaning they ascribed to race through the question, "What does the term 'race' mean to you?" and were instructed to make one selection from 10 responses: (1) biological group; (2) cultural group; (3) genetic ancestral group; (4) lifestyle/behavioral group; (5) population group; (6) religious group; (7) social identity group; (8) species; (9) none of the above; or (10) other. Similarly, respondents were asked, "What does the term 'ethnicity' mean to you?" and received similar instructions as above. We recoded and collapsed the responses into four categories: biological group (responses 1 and 8), genetic ancestral group (response 3 ), sociocultural group (responses 2, 4, 5, 6, and 7), and none of the above groups/other (responses 9 and 10).

\section{Statistical analysis}

We used descriptive statistics to examine the frequency with which physicians reported collecting race and ethnicity data and which method they used. We also used descriptive statistics to examine the comfort with collecting this data. Bivariate logistic regression and multinomial logistic regression were used to determine whether the demographic characteristics of the physicians, meanings of race and ethnicity, and patient panel were associated with respondents' comfort with and method of collecting patient race and ethnicity, respectively. Finally, multivariable linear regression was used to examine the associations of our two predictor variables-method of collection and comfort with collecting data on patient race and ethnicity - with the use of race in clinical decision-making, while adjusting for potential confounders, including physician demographics, practice characteristics, and meanings of race and ethnicity. All analyses were performed using SAS version 9.3.

\section{Results}

As previously reported, this sample of physician respondents represented a range of practice settings 
(Table 1). ${ }^{34,36}$ The sample of 787 general internists was predominately male $(65.3 \%)$, white $(67.1 \%)$, and had graduated from a United States medical school (75.4\%). United States medical graduates attended a broad range of medical schools, including schools in the District of Columbia, Puerto Rico, and 44 states. Most respondents reported a clinical location that was urban (96.4\%) and had a patient panel that was $>20 \%$ non-white $(74.0 \%)$. In addition, the study sample selfidentified race as white (67.1\%), black or African American (6.4\%), Asian (20.9\%), American Indian or Alaska
Native (1.2\%), Native Hawaiian or Other Pacific Islander $(0.3 \%)$, and/or other $(7.1 \%)$ and ethnicity as Hispanic or Latino (3.5\%) (Table 1).

More than half of the respondents either had their patients self-report their race and/or ethnicity on an intake form $(26.5 \%)$ or collected race and/or ethnicity directly from their patient $(26.2 \%)$ (Table 2$)$. Of the respondents, $84.3 \%$ reported being comfortable collecting patient race and ethnicity, $10.3 \%$ were uncomfortable, and $5.4 \%$ did not collect this information.

Table 1. Physician Characteristics and Use of Race in Clinical Decision-Making Scores

\begin{tabular}{|c|c|c|c|c|c|c|}
\hline Sample characteristics & $N$ & $\%$ & Mean (SD) & Mean RACE score (SD) & $p^{\mathrm{a}}$ & $\mathrm{AMA}^{\mathrm{b}}(\%)$ \\
\hline All physicians & 787 & - & - & $13.53(5.57)$ & & \\
\hline Mean age & 767 & - & $48.6^{c}(9.60)$ & - & - & - \\
\hline Sex (total, $N=774$ ) & & & & & 0.27 & \\
\hline Male & 505 & 65.25 & $50.37^{\mathrm{c}}(9.89)$ & $13.36(5.72)$ & & 67.2 \\
\hline Female & 269 & 34.75 & $45.31^{\mathrm{c}}(8.33)$ & $13.82(5.25)$ & & 32.8 \\
\hline \multicolumn{7}{|l|}{ Ethnicity (total, $N=767$ ) } \\
\hline Hispanic/Latino & 27 & 3.52 & - & $14.30(5.32)$ & - & 4.9 \\
\hline \multicolumn{7}{|l|}{ Race (total, $N=767)^{d}$} \\
\hline White & 515 & 67.14 & - & $12.87(5.45)$ & & 44 \\
\hline Black or African American & 49 & 6.39 & - & $14.56(6.11)$ & & 3.9 \\
\hline Asian & 160 & 20.86 & - & $15.24(5.53)$ & $<0.001$ & 17.4 \\
\hline American Indian/Alaska Native & 9 & 1.17 & - & $11.00(-)^{\mathrm{e}}$ & & 0.1 \\
\hline Native Hawaiian/Pacific Islander & 2 & 0.26 & - & $12.50(3.54)$ & & - \\
\hline Other & 54 & 7.04 & & $14.30(5.42)$ & & 2.3 \\
\hline \multicolumn{7}{|l|}{ Practice setting (total, $N=777$ ) } \\
\hline Academic health center & 89 & 11.45 & - & $12.66(6.03)$ & & - \\
\hline Federally qualified health center & 23 & 2.96 & - & $13.14(6.08)$ & & - \\
\hline Group or staff model practice HMO & 62 & 7.98 & - & $13.85(6.19)$ & & - \\
\hline Hospital based & 105 & 13.51 & - & $13.25(5.69)$ & 0.34 & - \\
\hline Office based & 459 & 59.07 & - & $13.86(5.27)$ & & - \\
\hline VA healthcare system & 15 & 1.93 & - & $12.79(5.28)$ & & - \\
\hline Other & 24 & 3.09 & - & $11.88(6.14)$ & & - \\
\hline $\begin{array}{l}\text { Patient population }>20 \% \text { minority } \\
\quad \text { (total, } N=720 \text { ) }\end{array}$ & 533 & 74.03 & - & $14.00(5.54)$ & $<0.001$ & \\
\hline \multicolumn{7}{|l|}{ Practice location (total, $N=725$ ) } \\
\hline Rural setting & 26 & 3.59 & - & $15.27(7.02)$ & 0.20 & - \\
\hline Urban setting & 699 & 96.41 & - & $13.43(5.46)$ & & - \\
\hline Percentage of work time seeing patients & 772 & - & $85(19.41)$ & - & - & \\
\hline \multicolumn{7}{|l|}{ Meaning of race (total, $N=775)^{\mathrm{d}}$} \\
\hline Biological group & 155 & 20.00 & - & $13.91(6.14)$ & & - \\
\hline Genetic ancestral group & 477 & 61.55 & - & $13.78(5.32)$ & 0.03 & - \\
\hline Sociocultural group & 125 & 16.13 & - & $12.48(5.63)$ & & - \\
\hline None of the above groups/other & 18 & 2.32 & - & $11.35(5.50)$ & & - \\
\hline \multicolumn{7}{|l|}{ Meaning of ethnicity (total, $N=775$ ) } \\
\hline Biological group & 31 & 4.00 & - & $13.77(5.35)$ & & - \\
\hline Genetic ancestral group & 125 & 16.13 & - & $14.16(5.51)$ & 0.37 & - \\
\hline Sociocultural group & 609 & 78.58 & - & $13.44(5.60)$ & & - \\
\hline None of the above groups/other & 10 & 1.29 & - & $11.50(4.67)$ & & - \\
\hline
\end{tabular}

${ }^{a} p$ Values are from $t$ tests or analysis of variance (if more than two groups) to compare mean scores for RACE score across physician characteristics. ${ }^{\mathrm{b}} N=160,107$. Data taken from the AMA's Physician Characteristics and Distribution in the US book, 2010 Edition.

'Denotes the mean age.

${ }^{\mathrm{d}}$ The $p$ values for the global $\mathrm{F}$ test of these analyses of variance (ANOVAs) indicate that at least one of the categories in each of the variables (physicians' race and meaning of race) has a mean RACE score that is significantly different from another category within the same variable.

${ }^{\mathrm{e}} \mathrm{SD}$ was not measurable because there was only one reported RACE score in this racial group.

-, Data not available.

RACE, Racial Attributes in Clinical Evaluation; SD, standard deviation; HMO, Health Maintenance Organization. 
Table 2. Frequencies of Race and Ethnicity Data Collection Methodologies and Comfort with Collection

\begin{tabular}{|c|c|c|}
\hline Item & Frequency & $\%$ \\
\hline \multicolumn{3}{|l|}{ Race and ethnicity data collection methodologies ${ }^{a}$} \\
\hline \multicolumn{3}{|l|}{ Patient reports } \\
\hline $\begin{array}{l}\text { The patient reports race or ethnicity on an } \\
\text { intake form }\end{array}$ & 205 & 26.45 \\
\hline \multicolumn{3}{|l|}{ Direct collection } \\
\hline $\begin{array}{l}\text { A clerk collects the patient's race or } \\
\text { ethnicity data directly from the patient }\end{array}$ & 73 & 9.42 \\
\hline $\begin{array}{l}\text { A nurse or physician's assistant collects } \\
\text { race or ethnicity directly from the patient }\end{array}$ & 21 & 2.71 \\
\hline $\begin{array}{l}\text { I (physician) collect race or ethnicity data } \\
\text { directly from the patient }\end{array}$ & 203 & 26.19 \\
\hline \multicolumn{3}{|l|}{ Perception-based collection } \\
\hline $\begin{array}{l}\text { I (physician) report patient's race or } \\
\text { ethnicity based upon my judgment }\end{array}$ & 121 & 15.61 \\
\hline $\begin{array}{l}\text { A clerk reports patient's race or ethnicity } \\
\text { based on his/her judgment }\end{array}$ & 6 & 0.77 \\
\hline $\begin{array}{l}\text { A nurse or physician's assistant reports } \\
\text { patient's race or ethnicity based on his/ } \\
\text { her judgment }\end{array}$ & 6 & 0.77 \\
\hline \multicolumn{3}{|l|}{ Not collected } \\
\hline These data are not collected & 140 & 18.06 \\
\hline \multicolumn{3}{|l|}{ Comfort with collecting race and ethnicity data ${ }^{\mathrm{b}}$} \\
\hline Comfortable & 654 & 84.30 \\
\hline Uncomfortable & 80 & 10.30 \\
\hline Never collect & 42 & 5.40 \\
\hline
\end{tabular}

${ }^{\mathrm{a}}$ Twelve physicians are missing from the count.

${ }^{b}$ Eleven physicians are missing from the count.

\section{Associations between physician characteristics}

with collection method and comfort collecting

race and ethnicity

Compared to minority physicians, respondents who self-reported as non-Hispanic white were less comfortable collecting patient race and ethnicity $(\beta=-0.27$ [95\% CI -0.52 to -0.00$]$ ) (Table 3). No other physician characteristics were significantly associated with collection method or comfort in the bivariate analysis.

\section{Association between method of and comfort with collecting data and use of race in clinical decision-making}

In the final multivariable regression model, physicians who used direct questioning collection of data on patient race and ethnicity compared with those who collected data using perception-based methods had significantly higher RACE scores $(\beta=1.24$ [95\% CI 0.07-2.41]) (Table 4). This finding does support our hypothesis that physicians who affirmatively collected race and ethnicity would be more likely to explicitly use it in clinical care.

Respondents who demonstrated increased levels of comfort collecting patient information were more inclined to use race in the clinical setting. In the bivariate analysis, the RACE score for physicians who were comfortable collecting race and ethnicity (14.06, standard deviation $[S D]=5.49)$ was significantly higher than those who were uncomfortable collecting race and ethnicity $(11.64, \mathrm{SD}=4.75)$ and those who never collected patient race and ethnicity $(9.00, \mathrm{SD}=5.83)$. This association persisted in the final multivariable model. After adjusting for physician demographic characteristics, it was found that physicians who were comfortable collecting data on patient race and ethnicity had somewhat greater use of race in clinical decision-making than those who were uncomfortable $(\beta=1.65[95 \%$ CI 0.03-3.28]) (Table 4). In addition, other variables that were significantly associated with higher use of patient race in the multivariable model included increased physician age, increased percent of time spent seeing patients, physician race (non-white vs. white), and patient panel ( $>20 \%$ minority vs. nonminority). Physician sex was not significantly associated with use of patient race.

\section{Discussion}

This study presents new knowledge on the collection of patient race and ethnicity by general internists and how this specific type of collection is related to and may impact clinical decision-making. Using data from a national survey of general internists, we found that more than half of the sample either asked patients to selfreport their race or ethnicity on an intake form or collected this information directly from patients during the clinical encounter. However, $35.3 \%$ of the study sample either collected race and ethnicity data using deductive methods (e.g., perception-based/observer report) $(17.2 \%)$ or did not collect such information at all (18.1\%). Our results support our first hypothesis regarding the notion that certain physician characteristics are associated with comfortability in collecting patient race or ethnicity data. Specifically, non-white physicians were more comfortable collecting race and ethnicity than white physicians. In addition, several characteristics were associated with an increased use of race in clinical decision-making, including physician race, age, comfort with collecting race and ethnicity, years in practice, percent of time spent seeing patients, and mode of collection of patient information. Our second hypothesis was also supported; there was no association between direct collection of race and its use in clinical care. We found in this study that physicians who used perceptionbased collection of data on patient race and ethnicity were more likely to use race in clinical care. Our third 
Table 3. Characteristics Associated with Method of and Comfort with Collecting Patient Race and Ethnicity Data

\begin{tabular}{|c|c|c|c|}
\hline Outcome & Characteristic & $\begin{array}{l}\text { Unadjusted parameter } \\
\text { estimate }[95 \% \mathrm{Cl}]^{\mathrm{a}}\end{array}$ & $p$ \\
\hline \multicolumn{4}{|l|}{ Method of collection } \\
\hline \multirow[t]{13}{*}{ Patient reports vs. perception based } & White, non-Hispanic vs. minority & $-0.04[-0.27$ to 0.20$]$ & 0.77 \\
\hline & Age & $-0.32[-2.45$ to 1.80$]$ & 0.76 \\
\hline & Female vs. male & $-0.03[-0.27$ to 0.21$]$ & 0.82 \\
\hline & Years in practice & $-0.50[-2.64$ to 1.63$]$ & 0.64 \\
\hline & $\%$ Time seeing patients & $-3.22[-7.39$ to 0.95$]$ & 0.13 \\
\hline & Patient panel > 20\% minority: yes vs. no & $-0.01[-0.30$ to 0.27$]$ & 0.94 \\
\hline & Meaning of race: biological vs. sociocultural group & $-0.27[-0.67$ to 0.13$]$ & 0.19 \\
\hline & Meaning of race: genetic ancestral vs. sociocultural group & $-0.22[-0.56$ to 0.12$]$ & 0.21 \\
\hline & Meaning of race: other/none vs. sociocultural group & $-0.88[-1.94$ to 0.18$]$ & 0.10 \\
\hline & Meaning of ethnicity: biological vs. sociocultural group & $0.25[-0.29$ to 0.80$]$ & 0.36 \\
\hline & Meaning of ethnicity: genetic ancestral vs. sociocultural group & $-0.02[-0.33$ to 0.28$]$ & 0.88 \\
\hline & Meaning of ethnicity: other/none vs. sociocultural group & $0.32[-0.58$ to 1.21$]$ & 0.49 \\
\hline & Practice location: rural vs. urban & $-0.11[-0.71$ to 0.49$]$ & 0.72 \\
\hline \multirow[t]{13}{*}{ Directly asking vs. perception based } & White, non-Hispanic vs. minority & $-0.07[-0.29$ to 0.15$]$ & 0.51 \\
\hline & Age & $-1.38[-3.37$ to 0.61$]$ & 0.17 \\
\hline & Female vs. male & $-0.01[-0.23$ to 0.21$]$ & 0.95 \\
\hline & Years in practice & $-1.51[-3.50$ to 0.48$]$ & 0.13 \\
\hline & $\%$ Time seeing patients & $-2.23[-6.13$ to 1.67$]$ & 0.26 \\
\hline & Patient panel $>20 \%$ minority: yes vs. no & $-0.19[-0.45$ to 0.06$]$ & 0.14 \\
\hline & Meaning of race: biological vs. sociocultural group & $-0.23[-0.60$ to 0.15$]$ & 0.23 \\
\hline & Meaning of race: genetic ancestral vs. sociocultural group & $-0.21[-0.53$ to 0.11$]$ & 0.19 \\
\hline & Meaning of race: other/none vs. sociocultural group & $0.03[-0.78$ to 0.83$]$ & 0.95 \\
\hline & Meaning of ethnicity: biological vs. sociocultural group & $-0.16[-0.70$ to 0.38$]$ & 0.56 \\
\hline & Meaning of ethnicity: genetic ancestral vs. sociocultural group & $-0.09[-0.37$ to 0.19$]$ & 0.52 \\
\hline & Meaning of ethnicity: other/none vs. sociocultural group & $-0.79[-1.85$ to 0.27$]$ & 0.14 \\
\hline & Practice location: rural vs. urban & $0.00[-0.54$ to 0.54$]$ & 0.99 \\
\hline \multicolumn{4}{|l|}{ Comfort collecting race and ethnicity } \\
\hline \multirow[t]{13}{*}{ Comfortable vs. uncomfortable } & White, non-Hispanic vs. minority & $-0.27[-0.52$ to -0.00$]$ & 0.05 \\
\hline & Age & $1.29[-0.97$ to 3.53$]$ & 0.26 \\
\hline & Female vs. male & $-0.10[-0.34$ to 0.14$]$ & 0.42 \\
\hline & Years in practice & $0.91[-1.37$ to 3.18$]$ & 0.44 \\
\hline & $\%$ Time seeing patients & $0.52[-3.94$ to 4.98$]$ & 0.82 \\
\hline & Patient panel > $20 \%$ minority: yes vs. no & $0.11[-0.20$ to 0.43$]$ & 0.47 \\
\hline & Meaning of race: biological vs. sociocultural group & $0.49[-0.12$ to 1.10$]$ & 0.12 \\
\hline & Meaning of race: genetic ancestral vs. sociocultural group & $0.16[-0.32$ to 0.64$]$ & 0.52 \\
\hline & Meaning of race: other/none vs. sociocultural group & $-0.22[-1.36$ to 0.92$]$ & 0.71 \\
\hline & Meaning of ethnicity: biological vs. sociocultural group & $0.37[-0.84$ to 1.58$]$ & 0.55 \\
\hline & Meaning of ethnicity: genetic ancestral vs. sociocultural group & $-0.05[-0.82$ to 0.73$]$ & 0.91 \\
\hline & Meaning of ethnicity: other/none vs. sociocultural group & $-0.15[-1.76$ to 1.45$]$ & 0.85 \\
\hline & Practice location: rural vs. urban & $0.19[-0.54$ to 0.92$]$ & 0.61 \\
\hline
\end{tabular}

${ }^{a}$ The unadjusted parameter estimate gives the probability for either comfort with or method of collection for every 1 unit increase (e.g., every 1 year increase in practice) or between the indicated group and the reference group (e.g., female vs. male). The reference group for method of collection was perception based. The reference group for comfort collecting race and ethnicity was uncomfortable.

hypothesis was supported; there was an association between comfort with collection and use of race, such that physicians who reported increased comfort with collecting patient information also used patient race more in decision-making.

The use of perception-based strategies to collect racial and ethnic data could be due to physicians' lack of comfort in discussing race and ethnicity with their patient, and thus greater reliance on inference, or due to racially and ethnically homogenous patient panels, which might deter collecting this information. We also theorize that physicians who employ this method are using a shortcut and are making fast, assumptive judgments. Physicians' communication style and com- fort level with collecting patients' race or ethnicity data may also be related to their attitudes regarding the importance of race, culture, or social determinants of health in identifying patients' risk of disease, understanding patients' attitudes toward care, and addressing potential barriers to engaging in healthy behaviors. Comfort levels may also reflect interpersonal cultural competence, which includes understanding the meaning of culture, appreciation of diversity, awareness of health disparities and discrimination affecting minority groups, and the ability to communicate effectively with patients of different racial and ethnic groups. ${ }^{37}$ Yet, comfort with collecting these data may not necessarily indicate competence. Although some programs have 
Table 4. Associations Between Physician Characteristics and Use of Race in Clinical Decision-Making

\begin{tabular}{|c|c|c|}
\hline Characteristic $(N=564)$ & $\begin{array}{l}\text { Parameter estimate } \\
{\left[[95 \% \mathrm{CI}]^{\mathrm{a}}\right.}\end{array}$ & $p$ \\
\hline \multicolumn{3}{|c|}{ Method of collection vs. perception based } \\
\hline Direct questioning & $1.24[0.07-2.41]$ & 0.04 \\
\hline Patient self-reports & $0.72[-0.52$ to 1.95$]$ & 0.26 \\
\hline \multicolumn{3}{|l|}{ Comfort collecting race and ethnicity } \\
\hline Comfortable vs. uncomfortable & $1.65[0.03-3.28]$ & 0.05 \\
\hline \multicolumn{3}{|l|}{ Sex } \\
\hline Females vs. males & $0.41[-0.56$ to 1.38$]$ & 0.40 \\
\hline Age & $0.17[0.05-0.30]$ & 0.005 \\
\hline \multicolumn{3}{|l|}{ Race } \\
\hline Minority vs. white, non-Hispanic & $1.13[0.13-2.13]$ & 0.03 \\
\hline Years in practice & $-0.13[-0.25$ to -0.01$]$ & 0.04 \\
\hline Percent time seeing patients & $0.03[0.00-0.05]$ & 0.04 \\
\hline \multicolumn{3}{|l|}{ Patient panel $>20 \%$ minority } \\
\hline Yes vs. no & $1.54[0.47-2.60]$ & 0.005 \\
\hline \multicolumn{3}{|c|}{ Definition of race vs. sociocultural group } \\
\hline Biological group & $1.44[-0.15$ to 3.03$]$ & 0.08 \\
\hline Genetic ancestral group & $0.97[-0.37$ to 2.31$]$ & 0.16 \\
\hline Other/none & $1.18[-2.61$ to 4.98$]$ & 0.54 \\
\hline \multicolumn{3}{|c|}{ Definition of ethnicity vs. sociocultural group } \\
\hline Biological group & $0.14[-2.17$ to 2.44$]$ & 0.91 \\
\hline Genetic ancestral group & $0.48[-0.76$ to 1.72$]$ & 0.45 \\
\hline Other/none & $-0.26[-4.60$ to 4.08$]$ & 0.91 \\
\hline
\end{tabular}

${ }^{\text {a }}$ The parameter estimate gives the change in RACE score for every 1 unit increase (e.g. every additional year for age) or between the indicated group and reference group (e.g. comfortable vs. uncomfortable).

been developed to train hospital, health system, and community health center staff in data collection methods, few cultural competence programs train physicians to discuss the impact of race and ethnicity on their patient's health in routine medical visits. ${ }^{1,27,38-42}$ Future work should examine these attitudes over time among physicians from different specialties and settings and investigate how communication style, methods of, and comfort with collecting race and ethnicity influence decision-making, disparities in healthcare delivery, and patient outcomes.

Given persistent disparities in healthcare and the importance of patient-physician relationships, studies that further explore the associations of provider communication style and comfort with collecting patient race and ethnicity with healthcare delivery in patients of different racial and ethnic groups could inform the development of interventions to improve quality of care and reduce disparities in treatment.

Race and ethnicity will continue to serve as important variables with which to measure quality of care in clinical practice and understand health disparities. For example, current law requires race, ethnicity, and language data collection for federally funded healthcare programs. ${ }^{43}$ It is important to note, however, that the use of race and ethnicity to measure quality of care and document health disparities in clinical care for populations differs from the use of race and ethnicity as proxies for disease risk or expected response to therapy in clinical decision-making for individual patients.

There are some limitations of this study. First, the surveyed general internists may not be representative of U.S. physicians from other specialties. Second, with the near-uniform use of electronic medical records today, there might be a shift in how patient race and ethnicity are collected by providers, which can influence their decision-making behaviors. ${ }^{44}$ Third, although we were able to find correlations (e.g., higher comfort was associated with higher RACE scores), it is unclear what factor(s) contributed to these relationships.

\section{Conclusion}

This study provides insights into physicians' comfort with collecting race and ethnicity and how these two classifications are currently used. Understanding how physicians engage patients in collecting sociodemographic information (e.g., race, ethnicity, and gender) can inform health equity research and medical education. While the concepts of race and ethnicity are socially meaningful, perceptions of their clinical utility vary ${ }^{45}$ and will likely evolve with the growth of genomic and precision medicine. ${ }^{46}$ Historically, race and ethnicity are concepts that have been used as heuristics. Studies of implicit bias suggest that physicians may use race as a heuristic to make medical decision-making more efficient, especially under conditions of high cognitive load. ${ }^{47}$ When used as a heuristic, however, race can obscure the use of other critically relevant clinical information needed for appropriate treatment because it may be based on a belief that racial groups are biologically discrete and/or culturally homogeneous, leading to the assumption that all individuals within these groups will react similarly to a therapy or treatment. ${ }^{48}$ Although the role of race and ethnicity in medicine is complex and contentious, race and ethnicity can be important for shaping healthcare experiences and access to care $^{49}$ for individual patients and for socially atrisk groups, making the collection of these data important and impactful for clinical practice, systems change, and policies aimed at improving health equity.

\section{Acknowledgments}

This research was supported, in part, by the Intramural Research Program of the National Human Genome Research Institute (ZIAHG200324-12). Dr. Cooper is 
supported by a grant from the National, Heart, Lung, and Blood Institute (K24HL083113) of the National Institutes of Health. The content is solely the responsibility of the authors and does not represent any position or policy of the National Human Genome Research Institute or the National Heart, Lung, and Blood Institute, National Institutes of Health.

\section{Author Disclosure Statement \\ No competing financial interests exist.}

\section{References}

1. Wilson G, Hasnain-Wynia R, Hauser D, et al. Implementing Institute of Medicine recommendations on collection of patient race, ethnicity, and language data in a community health center. J Health Care Poor Underserved. 2013;24:875-884.

2. Institute of Medicine. Race, ethnicity, language data: standardization for health care quality improvement. 2009. Available at www.ahrq.gov/sites/ default/files/publications/files/iomracereport.pdf Accessed March 15, 2017.

3. Temple R, Stockbridge NL. BiDil for heart failure in black patients: The U.S. Food and Drug Administration perspective. Ann Intern Med. 2007;146:57-62.

4. Johnson JA. Ethnic differences in cardiovascular drug response: potential contribution of pharmacogenetics. Circulation. 2008;118: 1383-1393.

5. Ramamoorthy A, Pacanowski MA, Bull J, et al. Racial/ethnic differences in drug disposition and response: review of recently approved drugs. Clin Pharmacol Therap. 2015;97:263-273.

6. Kumar R, et al. Genetic ancestry in lung-function predictions. N Engl J Med. 2010;363:321-330.

7. Food and Drug Administration. FDA clears test that helps predict the risk of coronary heart disease. 2015. Available at www.fda.gov/NewsEvents/ Newsroom/PressAnnouncements/ucm426799.htm Accessed March 15, 2017.

8. Rex DR, Johnson DA, Anderson JC, et al. American College of Gastroenterology Guidelines for Colorectal Cancer Screening 2008. Am J Gastroenterol 2009;104:739-750.

9. American Diabetes Association. American Diabetes Association releases position statement on new BMI screening cut points for diabetes in Asian Americans. 2014. Available at www.diabetes.org/newsroom/ press-releases/2014/american-diabetes-association-releases-positionstatement-on-new-bmi-screening-cut-points-for-diabetes-in-asianamericans.html?referrer=https://www.google.com Accessed March 15, 2017.

10. Lee SS, Mountain J, Koenig BA. The meanings of "race" in the new genomics: implications for health disparities research. Yale J Health Policy Law Ethics. 2001;1:33-75.

11. Wynia MK, Ivey SL, Hasnain-Wynia R. Collection of data on patients' race and ethnic group by physician practices. N Engl J Med. 2010; 362:846-850.

12. Anderson MR, Moscou S, Fulchon C, et al. The role of race in the clinical presentation. Fam Med. 2001;33:430-434.

13. Witzig R. The medicalization of race: scientific legitimization of a flawed social construct. Ann Intern Med. 1996;125:675-679.

14. Chin MH, Humikowski CA. When is risk stratification by race or ethnicity justified in medical care? Acad Med. 2002;77: 202-208.

15. van Ryn M, Burgess D, Malat J, et al. Physicians' perceptions of patients' social and behavioral characteristics and race disparities in treatment recommendations for men with coronary artery disease. Am J Public Health. 2006;96:351-357.

16. Egede LE. Race, ethnicity, culture, and disparities in health care. J Gen Intern Med. 2006;21:667-669.

17. Smedley BD, Stith AY, Nelson AR.; Institute of Medicine. Unequal Treatment: Confronting Racial and Ethnic Disparities in Health Care. Washington, DC: National Academies Press, 2003, p. 525.
18. Banda Y, Kvale MN, Hoffman TJ, et al. Characterizing race/ethnicity and genetic ancestry for 100,000 subjects in the genetic epidemiology research on Adult Health and Aging (GERA) Cohort. Genetics. 2015;200;1285-1295.

19. Taylor AL. Racial differences and racial disparities: the distinction matters. Circulation. 2015:131:848-850.

20. Smedley A, Smedley BD. Race as biology is fiction, racism as a social problem is real: anthropological and historical perspectives on the social construction of race. Am Psychol. 2005;60:16-26.

21. Cunningham BA. Race: a starting place. Virtual Mentor. 2014;16: 472-478.

22. Race $\mathrm{E}$, Genetics Working $\mathrm{G}$. The use of racial, ethnic, and ancestral categories in human genetics research. Am J Hum Genet. 2005;77: 519-532.

23. Yaeger R, Avila-Bront A, Abdul K, et al. Comparing genetic ancestry and self-described race in African Americans born in the United States and in Africa. Cancer Epidemiol Biomarkers Prev. 2008;17: 1329-1338.

24. Escarce JJ, Carreon R, Veselovskiy G, et al. Collection of race and ethnicity data by health plans has grown substantially, but opportunities remain to expand efforts. Health Aff (Millwood). 2011;30: 1984-1991.

25. Nerenz DR, Carreon R, Veselovskiy G. Race, ethnicity, and language data collection by health plans: findings from 2010 AHIPF-RWJF survey. J Health Care Poor Underserved. 2013;24:1769-1783.

26. Gazmararian J, Carreon R, Olson N, et al. Exploring health plan perspectives in collecting and using data on race, ethnicity, and language. Am J Manag Care. 2012;18:e254-e261.

27. Gomez SL, Lichtensztajn DY, Parikh P, et al. Hospital practices in the collection of patient race, ethnicity, and language data: a statewide survey, California, 2011. J Health Care Poor Underserved. 2014;25: 1384-1396.

28. Hasnain-Wynia R, Taylor-Clark K, Anise A. Collecting race, ethnicity, and language data to identify and reduce health disparities: perceptions of health plan enrollees. Med Care Res Rev. 2011;68: 367-381.

29. U.S. Department of Health and Human Services. Implementation guidance on data collection standards for race, ethnicity, sex, primary language, and disability status.2011. Available at http://aspe.hhs.gov/ datacncl/standards/ACA/4302/index.shtml\#Endnotes Accessed June 6 , 2015.

30. Blumenthal D. The "meaningful use" regulation for electronic health records. N Engl J Med. 2010;501-504.

31. Centers for Disease Control and Prevention. Meaningful use. 2017. Available at www.cdc.gov/ehrmeaningfuluse/introduction.html Accessed March 15, 2017.

32. Food and Drug Administration Office of Minority Health. Guidance for industry: collection of race and ethnicity in clinical trials. 2016. Available at www.fda.gov/downloads/Regulatorylnformation/Guidances/ ucm 126396.pdf Accessed March 15, 2017.

33. Hasnain-Wynia R, Baker DW. Obtaining data on patient race, ethnicity, and primary language in health care organizations: current challenges and proposed solutions. Health Serv Res. 2006;41(4 Pt 1): 1501-1518.

34. Bonham VL, Sellers SL, Woolford S. Physicians' knowledge, beliefs, and use of race and human genetic variation: new measures and insights. BMC Health Serv Res. 2014;14:456.

35. Internal Medicine Specialist List SK\&A2016. Available from www.skainfo com/databases/internal-medicine-specialist-list Accessed August 2, 2017.

36. Cunningham BA, Bonham VL, Sellers SL, et al. Physicians' anxiety due to uncertainty and use of race in medical decision making. Med Care. 2014;52:728-733.

37. Saha S, Beach MC, Cooper LA. Patient centeredness, cultural competence and healthcare quality. J Natl Med Assoc. 2008;100: $1275-1285$.

38. Hasnain-Wynia R, Weber DM, Yonek JC, et al. Community-level interventions to collect race/ethnicity and language data to reduce disparities. Am J Manag Care. 2012;18(Suppl 6):s141-s147.

39. Zingmond DS, Parikh $P$, Louie $R$, et al. Improving hospital reporting of patient race and ethnicity-approaches to data auditing. Health Serv Res. 2015;50 (Suppl 1):1372-1389. 
40. Like RC. Educating clinicians about cultural competence and disparities in health and health care. J Contin Educ Health. 2011;31:196-206

41. Beach MC, Price EG, Gary TL, et al. Cultural competence-a systematic review of health care provider educational interventions. Med Care. 2005:43:356-373.

42. Lie DA, Lee-Rey E, Gomez A, et al. Does cultural competency training of health professionals improve patient outcomes? A systematic review and proposed algorithm for future research. J Gen Intern Med. 2011; 26:317-325.

43. Patient Protection and Affordable Care Act (ACA). George Washington University's Hirsh Health Law and Policy Program and the Robert Wood Johnson Foundation, 2012.

44. Peters SG, Khan MA. Electronic health records: current and future use. J Comp Eff Res. 2014:3:515-522.

45. Braun L, Fausto-Sterling A, Fullwiley D, et al. Racial categories in medical practice: how useful are they? PLoS Med. 2007;4:e271.

46. Bonham VL, Callier SL, Royal CD. Will precision medicine move us beyond race? N Engl J Med. 2016;374:2003-2005.

47. Burgess DJ. Are providers more likely to contribute to healthcare disparities under high levels of cognitive load? How features of the healthcare setting may lead to biases in medical decision making. Med Decis Making. 2010;30:246-257.
48. Foster MW, Sharp RR. Race, ethnicity, and genomics: social classifications as proxies of biological heterogeneity. Genome Res. 2002;12: 844-850.

49. Koenig BA, Soo-Jin LS, Richardson SS. Revisiting race in a genomic age. In: Studies in Medical Anthropology. Edited by Marshall M. New Brunswick, NJ: Rutgers University Press, 2008, pp. 97-99.

Cite this article as: Bonham VL, Umeh NI, Cunningham BA, Abdallah KE, Sellers SL, Cooper LA (2017) Primary care physicians' collection, comfort, and use of race and ethnicity in clinical practice in the United States, Health Equity 1:1, 118-126, DOI: 10.1089/heq.2017.0015.

\section{Abbreviations Used}

AIMS $=$ ancestral informative markers $\mathrm{Cl}=$ confidence interval

RACE $=$ Racial Attributes in Clinical Evaluation Scale $\mathrm{SD}=$ standard deviation

SIRE $=$ self-identified race and ethnicity

\section{Publish in Health Equity}

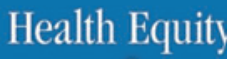

- Immediate, unrestricted online access

- Rigorous peer review

- Compliance with open access mandates

- Authors retain copyright

- Highly indexed

- Targeted email marketing

liebertpub.com/heq 